\title{
Genetic Analysis of Number of Mastitis Cases and Number of Services to Conception Using a Censored Threshold Model
}

\author{
B. Heringstad, ${ }^{\star} \dagger^{1}$ Y. M. Chang, $¥$ I. M. Andersen-Ranberg, $†$ and D. Gianola* $¥$ \\ *Department of Animal and Aquacultural Sciences, Norwegian University of Life Sciences, PO Box 5003, N-1432 Ås, Norway \\ †Geno Breeding and A. I. Association, PO Box 5003, N-1432 Ås, Norway \\ ‡Department of Dairy Science, University of Wisconsin, Madison 53706
}

\section{ABSTRACT}

The objective of this study was to infer genetic parameters and genetic change for number of clinical mastitis cases (NCM) and number of services to conception (STC) in first-lactation Norwegian Red (NRF) cows. Records on 620,492 daughters of 3,064 NRF sires, with first calving from 1980 through 2004, were analyzed with a bivariate threshold liability model that takes censoring into account. Posterior mean (SD) of heritability of liability was 0.08 (0.004) for NCM and 0.03 (0.002) for STC. The mean (SD) of the posterior distribution of the genetic correlation between the 2 traits was 0.21 (0.04). Posterior means of the correlation between herd-5-yr effects, and between residuals for NCM and STC were 0.17 and 0.05 , respectively. To evaluate effects of taking censoring into account, the data were also analyzed with a bivariate ordered threshold model ignoring censoring. The genetic correlation between NCM and STC was lower than in the censored threshold model (0.09 vs. 0.21$)$. Heritability of liability to NCM and STC from this model was also slightly lower, whereas the point estimates of herd-5-yr and residual correlations were 0.15 , and -0.01 , respectively. These results suggest that genetic (co)variance may be understated in models ignoring censoring. For comparison purposes, the data were analyzed with a bivariate linear sire model and standard REML-BLUP procedures. The correlation (rank correlation) between sire evaluations from the censored threshold model and sire predicted transmitting abilities from the linear model was $0.90(0.90)$ for NCM and 0.87 (0.86) for STC. The evolution of average sire posterior means by birth year of daughters was used to assess genetic change, and results indicated genetic reduction (i.e., genetic improvement) of NCM and little or no genetic change for STC in the NRF population.

Key words: clinical mastitis, censoring, female fertility, threshold model

Received March 10, 2006.

Accepted May 23, 2006.

${ }^{1}$ Corresponding author: bjorg.heringstad@umb.no

\section{INTRODUCTION}

Strategies for improving health and fertility are necessary to reduce costs of dairy production. Both mastitis and female fertility have been included in the total merit index used for selection of Norwegian Red (NRF) sires since the 1970s. The traits absence or presence of clinical mastitis $(\mathbf{C M})$ in the interval from $15 \mathrm{~d}$ before to $120 \mathrm{~d}$ after first calving and nonreturn rate within $56 \mathrm{~d}$ (NR) after first insemination have been used in genetic evaluation.

There are few studies on genetic associations between health and fertility in dairy cattle. Zwald et al. (2004a) found a correlation of -0.11 between PTA for daughter pregnancy rate (from USDA routine evaluation) and PTA for probability of mastitis. Kadarmideen et al. (2000) estimated genetic parameters for various diseases and fertility traits for UK Holstein cattle, and found that higher mastitis incidence was genetically associated with reduced fertility, with genetic correlations (absolute value) ranging from 0.21 to 0.41 . Estimates of the genetic correlation between number of clinical mastitis cases (NCM) and number of services to conception (STC) are not available in the literature. In genetic evaluation, both mastitis and female fertility are often treated as binary traits. For mastitis, the binary variable takes value 1 if a cow has at least one $\mathrm{CM}$ case within a given time interval, and 0 otherwise. Likewise, the fertility trait NR takes value 0 if a cow has a second insemination within $56 \mathrm{~d}$ after a first one, and 1 otherwise. With these binary traits, cows with one or more cases of mastitis are treated as equally liable to the disease, and cows with one or multiple returns after insemination are scored as equally fertile. An alternative is to use NCM and STC as response variables.

A reason why these traits are not used more widely is the existence of censoring of information: cows with mastitis or fertility problems are more likely to be culled than healthy, fertile cows. The risk of culling increases as NCM or STC increase.

Chang et al. (2006) developed an ordinal threshold model that takes random censoring into account. The 
Table 1. Distribution of cows (\%) over number of clinical mastitis cases (NCM) categories

\begin{tabular}{llll}
\hline $\mathrm{NCM}^{1}$ & $\begin{array}{l}\text { All } \\
\text { cows }\end{array}$ & $\begin{array}{l}\text { Censored } \\
\text { cows }\end{array}$ & $\begin{array}{l}\text { Uncensored } \\
\text { cows }\end{array}$ \\
\hline 0 & 81 & 77 & 82 \\
1 & 16 & 19 & 15 \\
$\geq 2$ & 3 & 4 & 3 \\
\hline
\end{tabular}

${ }^{1} \mathrm{NCM}$ was defined as the number of clinical mastitis $(\mathrm{CM})$ treatments during first lactation, in 3 categories: 0,1 , and 2 or more cases of CM.

objective of this study was to extend this model to a bivariate setting for 2 ordered categorical traits, and to infer genetic parameters and genetic change for NCM and STC in NRF. To examine the effect of accommodating censoring, parameter estimates and genetic evaluation of sires from this model were compared with those from a threshold model ignoring censoring, and with those found with a linear sire model.

\section{MATERIALS AND METHODS}

\section{Data}

Health and fertility data was extracted from the Norwegian Dairy Herd Recording System. The data set consisted of records from 620,492 first-lactation daughters of 3,064 NRF sires. Only daughters from progeny test were included (i.e., difference between birth year of daughter and birth year of sire $<6 \mathrm{yr}$ ). First calving had to be between 1980 and 2004, and age at first calving was between 20 and 40 mo. The data set was restricted further to include only cows from herd-5-yr classes with at least 5 first-lactation cows with uncensored NCM records and from sires with at least 20 daughters.

For each cow, CM records from $30 \mathrm{~d}$ before first calving to culling, $300 \mathrm{~d}$ after first calving, or second calving, whichever occurred first, were included. Number of clinical mastitis cases was the number of $\mathrm{CM}$ treatments during first lactation, in 3 categories: 0,1 , and 2 or more cases of $\mathrm{CM} ; 81 \%$ of the cows had no CM during first lactation, $16 \%$ had 1 case, and $3 \%$ of the cows had 2 or more cases. Cases were considered distinct when veterinary treatment was given more than $5 \mathrm{~d}$ apart, to avoid counting repeated treatments of the same case as different mastitis episodes. If a cow was culled before $300 \mathrm{~d}$ after first calving, her NCM record was considered censored at random. The overall censoring rate for mastitis was $30 \%$. Mean NCM was higher for censored (0.27) than for noncensored (0.21) cows. The distribution of cows over NCM categories is given in Table 1.

A total of $460,445(74 \%)$ of the cows had at least 1 insemination. Double insemination was defined as a
Table 2. Distribution of cows (\%) over number of services to conception (STC) categories

\begin{tabular}{llll}
\hline STC $^{1}$ & $\begin{array}{l}\text { All } \\
\text { cows }\end{array}$ & $\begin{array}{l}\text { Censored } \\
\text { cows }\end{array}$ & $\begin{array}{l}\text { Uncensored } \\
\text { cows }\end{array}$ \\
\hline 1 & 61 & 50 & 63 \\
2 & 26 & 29 & 25 \\
3 & 9 & 14 & 8 \\
4 & 3 & 5 & 3 \\
$\geq 5$ & 1 & 2 & 1 \\
\hline
\end{tabular}

${ }^{1} \mathrm{STC}$ was defined as the number of inseminations in first lactation, in 5 categories.

new insemination occurring 0 to $5 \mathrm{~d}$ after a first insemination. For each cow, all services in first lactation, other than double inseminations, were counted. Number of services to conception had 5 categories, with an overall mean of 1.6. Cows that had received reproductive veterinary treatment were not included ( $8 \%$ of first-lactation cows). Cows without a record of second calving (16\%) were considered censored for STC. Mean STC was 1.5 for noncensored and 1.8 for censored cows. The distribution of cows over STC categories is given in Table 2. Mean NCM was higher for cows with missing STC $(0.26)$ than for cows with STC records (0.21).

The sire pedigree file was built by tracing the pedigree through sires and maternal grandsires back as far as possible. The resulting file had 3,756 males, including the 3,064 sires with daughter records in the data set.

\section{Censored Threshold Model}

A bivariate threshold-liability model (Gianola and Foulley, 1983; Foulley et al., 1987) was used for analysis of the categorical NCM and STC. For each trait, the threshold model postulates an underlying continuous variable, liability $(\lambda)$, such that the observed categorical variable takes value $j$ if $\mathrm{T}_{\mathrm{j}-1} \leq \lambda<\mathrm{T}_{\mathrm{j}}$, where $\mathrm{T}_{\mathrm{j}-1}$ and $\mathrm{T}_{\mathrm{j}}$ are thresholds, and $j=1,2, \ldots, \mathrm{J}$ indexes the categories to which an observation belongs. The thresholds must satisfy $-\infty=\mathrm{T}_{0} \leq \mathrm{T}_{1} \leq \mathrm{T}_{2} \leq \ldots \leq \mathrm{T}_{\mathrm{J}}=\infty$. The first threshold $\mathrm{T}_{1}$ is set to zero, because the parameter cannot be identified in a probit analysis. If an observation in category $j$ is censored, its corresponding liability must be $\geq T_{j-1}$. The fitted model allowed for censoring of either trait. In matrix notation the model fitted can be written as:

$$
\lambda=\mathbf{X} \boldsymbol{\beta}+\mathbf{Z}_{\mathbf{h}} \mathbf{h}+\mathbf{Z}_{\mathbf{s}} \mathbf{s}+\mathrm{e}
$$

where $\lambda$ is a vector of unobserved liabilities of NCM and STC; $\beta$ is a vector of trait-specific systematic effects, including age at first calving in months (21 levels) and month-year of first calving (288 levels) effects; $\mathbf{h}$ is a vector of herd-5-yr period of calving effects $(51,808 \mathrm{lev}$ els); $\mathbf{s}$ is a vector of sire transmitting abilities; $\mathbf{e}$ is a 
vector of residuals, and $\mathbf{X}, \mathbf{Z}_{\mathbf{h}}$, and $\mathbf{Z}_{\mathrm{s}}$ are the corresponding incidence matrices. Residual variances for the 2 traits were set equal to 1 . Residuals were assumed to be independent between cows and correlated within cows, and to follow the normal distribution

$$
\mathbf{e} \sim N(\mathbf{0}, \mathbf{R} \otimes \mathbf{I})
$$

where $\mathbf{R}=\left[\begin{array}{cc}1 & \sigma_{e 1 e 2} \\ \sigma_{e 1 e 2} & 1\end{array}\right]$ is the residual (co)variance matrix and $\mathbf{I}$ is an identity matrix.

A Bayesian approach using Markov chain Monte Carlo (MCMC) methods (e.g., Sorensen and Gianola, 2002), as applied by Chang et al. (2006), was implemented.

Prior Distributions. Independent proper uniform priors were adopted for each of the elements of $\beta$. Multivariate normal prior distributions were assigned to herd-5-yr effects, $\mathbf{h} \sim N\left(\mathbf{0}, \mathbf{H}_{0} \otimes \mathbf{I}\right)$, and to sire effects, $\mathbf{s} \sim N\left(\mathbf{0}, \mathbf{G}_{0} \otimes \mathbf{A}\right)$, where $\mathbf{H}_{\mathbf{0}}$ and $\mathbf{G}_{\mathbf{0}}$ are the $2 \times 2$ (co)variance matrices of herd-5-yr and sire effects, respectively, and $\mathbf{A}$ is the matrix of additive relationships between sires. Inverse Wishart prior distributions, with 4 degrees of freedom, were used for the (co)variance matrices of herd-5-yr and sire effects, and the residual covariance or correlation $\left(\sigma_{\mathrm{e} 1 \mathrm{e} 2}\right)$ was assigned a uniform prior bounded between -1 and 1 . Thresholds were assumed to be distributed as ordered statistics from a uniform distribution, where $0 \leq \mathrm{T}_{2} \leq \ldots \leq \mathrm{T}_{\mathrm{J}-1}$.

Sampling and Convergence Diagnostics. Draws from the posterior distributions of the parameters, except for the thresholds and residual correlation, were obtained using a Gibbs sampler (Sorensen and Gianola, 2002). For cows that did not have data for STC, "missing liabilities" were included in the augmented posterior distribution. The method of Albert and Chib (1997) was used for sampling thresholds, using a Metropolis algorithm, as described by Chang et al. (2006). Based on the convergence diagnostics method of Raftery and Lewis (1992) and on visual inspection of trace plots, a chain of 100,000 iterations was run. The first 10,000 rounds were discarded as "burn in," and all the remaining 90,000 samples were kept for posterior analyses. The effective sample size for the parameters varied from 3,935 (fourth threshold for STC) to 30,405 (residual correlation). Acceptance rate for the Metropolis algorithms were $46 \%$ for thresholds for NCM, 39\% for thresholds for STC, and $40 \%$ for residual correlations.

Sire Evaluations. Sire evaluations based on MCMC methods have Monte Carlo error, which can be made arbitrarily small, depending on computational feasibility. Two additional chains, with different seeds, were run, and correlations between sire posterior means from the 3 chains were used to evaluate the impact of Monte Carlo error on sire evaluations.

Genetic Change. Genetic change was assessed by plotting average sire posterior means against birth year of daughters. All daughters of the 3,064 sires (1.8 million cows) were used for assessment of genetic change. Sires were weighted according to their number of daughters, so this measure reflects sire usage as well as possible genetic change in the NRF population.

\section{Threshold Model Ignoring Censoring}

To evaluate the effect of taking censoring into account, the bivariate threshold model described above was also run ignoring censoring; that is, with all records treated as uncensored.

\section{Linear Model Analysis}

For comparison, the data were also analyzed with a bivariate linear sire model and standard REML-BLUP procedures, using the DMU package (Madsen and Jensen, 2005), ignoring censoring and the categorical nature of the traits. Here, response variables were NCM and STC, and explanatory variables were those in the censored threshold model.

\section{RESULTS AND DISCUSSION}

\section{Heritability}

Posterior means and SD of parameters from the censored threshold model are given in Table 3 . The posterior distribution of heritability of liability to NCM was sharp and symmetric (Figure 1) with posterior mean (SD) of 0.08 (0.004) (Table 3). This is within the range of estimates from cross-sectional threshold model analyses of first-lactation mastitis treated as a single binary trait, which range from 0.06 to 0.12 (Lund et al., 1999; Heringstad et al., 2003; Zwald et al., 2004b). Heritability of liability to binary CM in the same data set (B. Heringstad, unpublished data) was slightly lower (0.07 vs. 0.08); the small difference is not surprising, because $97 \%$ of the records were in the 0 and 1 classes. Lund et al. (1999) and Sørensen et al. (2000) using linear model analyses found that the heritability of counts of clinical mastitis cases was not higher than that of clinical mastitis treated as a binary trait.

The posterior mean (SD) of heritability of liability to STC of $0.03(0.002)$ was in agreement with other threshold model estimates (González-Recio et al., 2005; Chang et al., 2006), which ranged between 0.03 and 0.05 . Linear model estimates of heritability of STC ranged between 0.02 and 0.03 (Hayes et al., 1992; Roxström et al., 2001; Veerkamp et al., 2001; Wall et al., 
Table 3. Mean and standard deviation (SD) of posterior distributions of sire, herd-5-yr and residual (co)variances, thresholds, heritabilities, and genetic, herd-5-yr, and residual correlations from the bivariate censored threshold model analysis of liability to number of clinical mastitis cases (NCM) and number of services to conception (STC)

\begin{tabular}{|c|c|c|c|c|c|c|}
\hline \multirow[b]{2}{*}{ Parameter } & \multicolumn{2}{|c|}{$\mathrm{NCM}$} & \multicolumn{2}{|c|}{ STC } & \multicolumn{2}{|c|}{ NCM and STC } \\
\hline & Mean & SD & Mean & $\mathrm{SD}$ & Mean & $\mathrm{SD}$ \\
\hline (Co)variance, sire & 0.024 & 0.001 & 0.008 & 0.0005 & 0.003 & 0.0005 \\
\hline (Co)variance, herd-5-yr & 0.14 & 0.002 & 0.06 & 0.001 & 0.01 & 0.001 \\
\hline (Co)variance, residual & 1 & 0 & 1 & 0 & 0.05 & 0.002 \\
\hline Threshold 2 & 0.95 & 0.003 & 0.82 & 0.002 & & \\
\hline Threshold 3 & & & 1.43 & 0.004 & & \\
\hline Threshold 4 & & & 1.95 & 0.006 & & \\
\hline Heritability ${ }^{1}$ intraherd & 0.09 & 0.004 & 0.03 & 0.002 & & \\
\hline Heritability $^{2}$ & 0.08 & 0.004 & 0.03 & 0.002 & & \\
\hline Genetic correlation & & & & & 0.21 & 0.039 \\
\hline Herd-5-yr correlation & & & & & 0.17 & 0.010 \\
\hline Residual correlation & & & & & 0.05 & 0.002 \\
\hline
\end{tabular}

${ }^{1}$ Intraherd heritability: $\mathrm{h}^{2}=4 \sigma_{\mathrm{s}}^{2} /\left(\sigma_{\mathrm{s}}^{2}+\sigma_{\mathrm{e}}^{2}\right)$, where $\sigma_{\mathrm{s}}^{2}=$ sire variance and $\sigma_{\mathrm{e}}^{2}=$ residual variance.

${ }^{2} \mathrm{~h}^{2}=4 \sigma_{\mathrm{s}}^{2} /\left(\sigma_{\mathrm{s}}^{2}+\sigma_{\mathrm{h}}^{2}+\sigma_{\mathrm{e}}^{2}\right)$, where $\sigma_{\mathrm{s}}^{2}=$ sire variance, $\sigma_{\mathrm{h}}^{2}=$ herd-5-yr variance, and $\sigma_{\mathrm{e}}^{2}=$ residual variance.

2003). Figure 1 indicates that it is unlikely that heritability of liability to STC exceeds 0.035 in the NRF population.

\section{Correlations}

The posterior distribution of the genetic correlation between NCM and STC from the censored threshold model was sharp and symmetric (Figure 2), with posterior mean (SD) of $0.21(0.039)$. The genetic correlation is favorable, in the sense that selection for lower NCM is expected to result in some positive correlated response in fertility (fewer STC), and vice versa. The correlation between herd-5-yr effects was also positive (0.17) whereas the residual correlation between the 2 traits was close to zero (Table 3). This suggests that herds with high NCM tend to have higher STC.

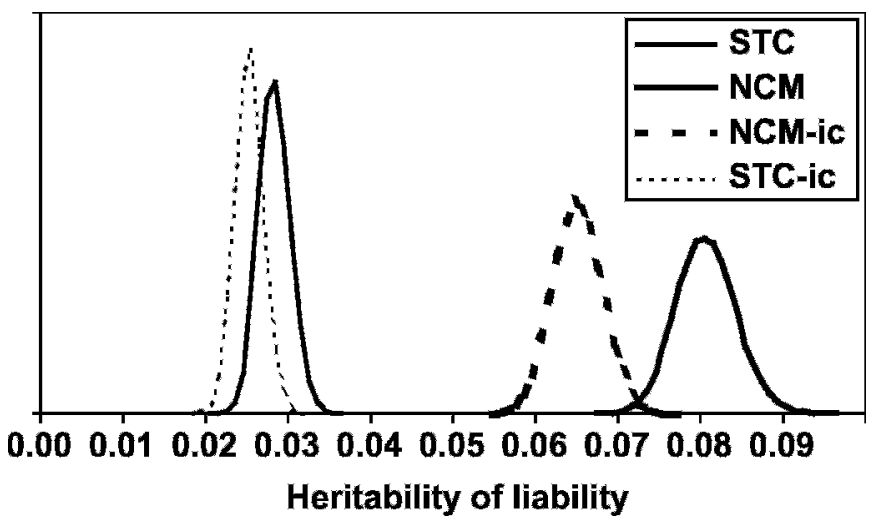

Figure 1. Posterior distributions of heritability $\left[\mathrm{h}^{2}=\right.$ $\left.4 \sigma_{\mathrm{s}}^{2} /\left(\sigma_{\mathrm{s}}^{2}+\sigma_{\mathrm{h}}^{2}+\sigma_{\mathrm{e}}^{2}\right)\right]$ of liability to number of clinical mastitis cases (NCM) and number of services to conception (STC) from censored threshold model and from a threshold model ignoring censoring (-ic).

\section{Thresholds}

For each trait the first threshold was set to zero. The posterior mean (SD) of the second threshold for NCM was $0.95(0.003)$. Number of services to conception had 5 categories, and the point estimates of thresholds 2 , 3 , and 4 were $0.82,1.43$, and 1.95 , respectively (Table 3 , which are very similar to estimates reported by Chang et al. (2006).

\section{Model Limitations and Assumptions}

This model takes censoring into account. However, some potential problems remain unresolved, such as nonrandom censoring over sires, and nonrandom missing records. Nonrandom censoring may occur because the risk of culling (and, thus, of censoring) increases as

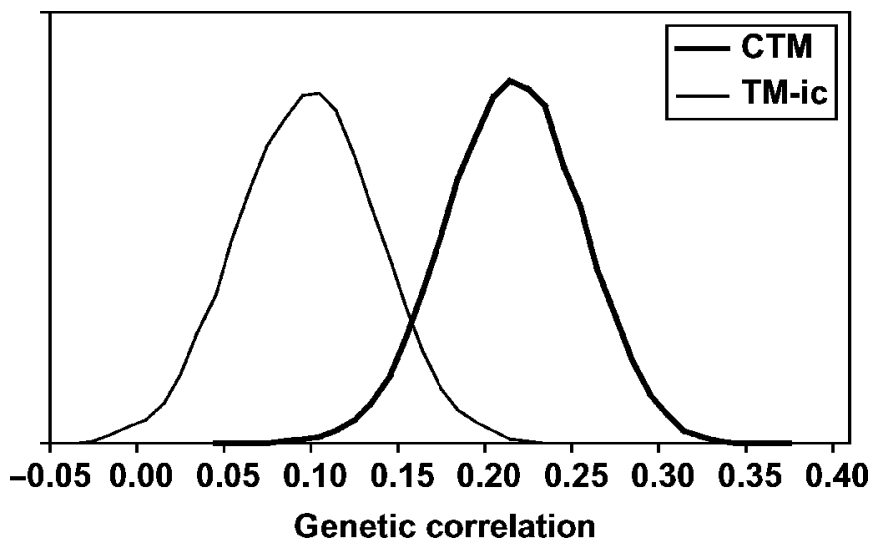

Figure 2. Posterior distribution of the genetic correlation between number of clinical mastitis cases and number of services to conception from a censored threshold model (CTM) and from a threshold model ignoring censoring (TM-ic). 
Table 4. Posterior mean (standard deviation) of heritabilities, and genetic, herd-5-yr, and residual correlations between number of clinical mastitis cases (NCM) and number of services to conception (STC), from censored threshold model (TM) and TM ignoring censoring, together with linear model estimates

\begin{tabular}{llrc}
\hline Parameter & Censored TM & $\begin{array}{l}\text { TM ignoring } \\
\text { censoring }\end{array}$ & $\begin{array}{l}\text { Linear } \\
\text { model } \\
\text { estimates }\end{array}$ \\
\hline Heritability ${ }^{1}$ NCM & $0.08(0.004)$ & $0.07(0.003)$ & 0.03 \\
Heritability ${ }^{1}$ STC & $0.03(0.002)$ & $0.03(0.002)$ & 0.02 \\
Genetic correlation & $0.21(0.039)$ & $0.09(0.040)$ & 0.10 \\
Herd-5-yr correlation & $0.17(0.014)$ & $0.15(0.014)$ & 0.15 \\
Residual correlation & $0.05(0.002)$ & $-0.01(0.002)$ & -0.01 \\
\hline
\end{tabular}

${ }^{1}$ Heritability: $\mathrm{h}^{2}=4 \sigma_{\mathrm{s}}^{2} /\left(\sigma_{\mathrm{s}}^{2}+\sigma_{\mathrm{h}}^{2}+\sigma_{\mathrm{e}}^{2}\right)$, where $\sigma_{\mathrm{s}}^{2}=$ sire variance, $\sigma_{\mathrm{h}}^{2}=$ herd-5-yr variance, and $\sigma_{\mathrm{e}}^{2}=$ residual variance.

NCM or STC increases. Cows with no insemination after first calving had missing STC (26\% of the cows). These cows were candidates for culling during or after first lactation, and did not represent a random sample of cows with respect to traits such as health and fertility. However, if culling were due to mastitis or fertility problems, the effect of missing records would be ignorable (Im et al., 1989), because selection then would have been based on data that were included in the analysis. Also, cows culled early in lactation have a shorter opportunity period than cows culled late in lactation. Censoring time was not accounted for in the current model.

Andersen-Ranberg et al. (2003) found that service sire accounted for a very small fraction of the variation of fertility in NRF. Therefore, in the current study, service sire was not included in the model for STC. One way of including (partially) effects of service sires in an ordinal threshold model, is to fit first service sire as a factor, as in González-Recio et al. (2005).

A normal distribution of the liability variate was assumed for both traits. Poisson models, or for NCM, a zero-inflated Poisson model (Rodrigues-Motta et al., 2006), may be an alternative for genetic analysis of these traits.

Associations with other traits, for example milk production, were not accounted for in the present model. One alternative would be to extend the current model and analyze milk, mastitis, and fertility in a multitrait model. Another option is to develop a structural model (Gianola and Sorensen, 2004), and fit causal relationships from milk to health and fertility. All these are subjects for further research.

\section{Effect of Taking Censoring into Account}

Table 4 shows that heritability estimates from the threshold models (liability scale) were higher than corresponding linear model estimates. This was expected, and in agreement with previous studies (Heringstad et
Table 5. The top 10 sires for STC based on sire posterior mean (SPM) from the censored threshold model (TM) and their ranking based on SPM from TM ignoring censoring and linear model PTA

\begin{tabular}{lcc}
\hline Censored TM & $\begin{array}{l}\text { TM ignoring } \\
\text { censoring }\end{array}$ & $\begin{array}{l}\text { PTA linear } \\
\text { model }\end{array}$ \\
\hline 1 & 1 & 3 \\
2 & 3 & 568 \\
3 & 2 & 1 \\
4 & 6 & 19 \\
5 & 15 & 364 \\
6 & 5 & 14 \\
7 & 10 & 13 \\
8 & 7 & 627 \\
9 & 4 & 4 \\
10 & 14 & 22 \\
\hline
\end{tabular}

al., 2003; Andersen-Ranberg et al., 2005). Relative to a threshold model ignoring censoring, in which censored records were treated as "complete" (Table 4), the censored threshold model produced higher heritability estimates for both traits, and a larger genetic correlation (0.21 vs. 0.09 ) as shown in Figures 1 and 2. Residual correlation was close to zero, and the herd-5-yr correlation was similar in all 3 models.

A formal model comparison was not performed. Because the data are different when censoring is taken into account compared with when this information is ignored, a comparison (e.g., in terms of the Bayes factor) is not appropriate here. The analysis shows that taking censoring into account affects parameter estimation, and the better model is arguably the one that uses all available information.

\section{Sire Evaluations}

Correlations of 0.9999 between sire posterior means from 3 different chains of the censored threshold model indicated small Monte Carlo error on the sire evaluations for both NCM and STC in this analysis.

The correlation (rank correlation) between sire evaluations from the censored threshold model and from the linear model was $0.90(0.90)$ for NCM and $0.87(0.86)$ for STC. The rank correlation between sire evaluations from the 2 threshold models was 0.97 for NCM and 0.96 for STC. Table 5 shows how the top 10 sires for STC from the censored threshold model ranked based on evaluation form a threshold model ignoring censoring and based on PTA from a linear sire model. For some sires there was reasonably good agreement between the 3 evaluations (e.g., sires number 1 and 3), whereas for others (e.g., sires 2 and 5), there were large differences between models. For STC there were only 3 common bulls ranked within the top 10 for both the censored threshold model and the linear model. Within one batch of bulls born in 1997 (140 bulls), the number of common 


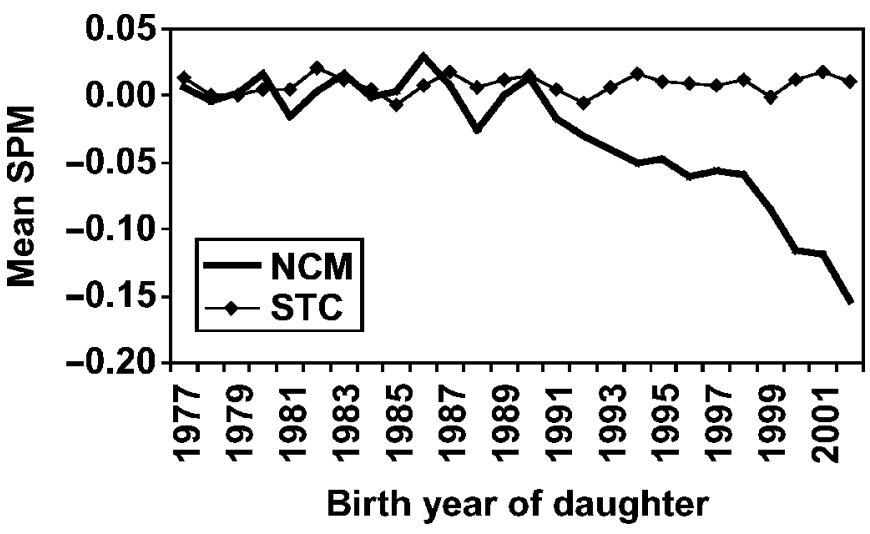

Figure 3. Genetic change for number of clinical mastitis cases (NCM) and number of services to conception (STC) in first-lactation Norwegian Red cows given as average sire posterior mean (SPM) by birth-year of daughters.

bulls among the top 10 for the censored threshold model and the linear model were 7 for both traits.

\section{Genetic Change}

Averages of sire posterior means for NCM and STC plotted by birth year of daughters are given in Figure 3. There was little or no genetic change for STC, but genetic improvement for NCM for first-lactation NRF cows was evident. Number of cases of clinical mastitis showed a similar trend as CM (Heringstad et al., 2003); this is expected, because NCM and binary CM have a genetic correlation of 0.96 (Andersen-Ranberg and Heringstad, 2006). Clinical mastitis has been included in the total merit index used for selection of NRF sires in Norway since 1978. The relative weight on CM in this index has gradually increased from less than $3 \%$ in 1978 to $21 \%$ in 2004 (Heringstad et al., 2001; Geno, 2006).

Female fertility has been included in the total merit index for NRF since 1972, with relative weight between 8 and 15\% (Andersen-Ranberg, 2005). The trait used for genetic evaluation has been NR in virgin heifers and, since 2002, NR in virgin heifers and first-lactation cows. So far, STC has not been used in genetic evaluation of NRF sires. However, STC is genetically correlated with traits on which selection pressure is exerted (Andersen-Ranberg and Heringstad, 2006), such as milk yield (unfavorable, 0.40), mastitis (favorable, 0.21 ), and NR (favorable, 0.98). Figure 3 indicates that the genetic change for STC in NRF has been close to zero.

\section{CONCLUSIONS}

Point estimates of heritability of liability were 0.08 for NCM and 0.03 for STC. The genetic correlation be- tween the 2 traits was 0.21. Assessment of genetic change in the NRF population indicated genetic improvement of NCM and no genetic change for STC.

Results indicate that censoring affects parameter estimation as well as genetic evaluation and ranking of sires. Genetic (co)variance between NCM and STC seems to be underestimated in models ignoring censoring. With a model that takes censoring into account, NCM and STC may become more appealing candidate traits for genetic evaluation of mastitis and fertility.

\section{ACKNOWLEDGMENTS}

Access to the data was given by the Norwegian Dairy Herd Recording System and the Norwegian Cattle Health Service in agreement number 004.2005. This work is part of project no 167893/I10 ("Avl for friskere kyr") financed by the Research Council of Norway. Support was also received from the Babcock Institute for International Dairy Research and Development, University of Wisconsin, Madison. Financial support by the Wisconsin Agriculture Experiment Station, and grants NRICGP/USDA 2003-35205-12833, NSF DEB0089742, and NSF DMS-0443771 is acknowledged.

\section{REFERENCES}

Albert, J. H., and S. Chib. 1997. Bayesian methods for cumulative, sequential and two-step ordinal data regression models. Technical Report. Department of Mathematics and Statistics, Bowling Green State University, Bowling Green, $\mathrm{OH}$.

Andersen-Ranberg, I. M. 2005. Genetics of dairy cow fertility. PhD Thesis, Norwegian University of Life Sciences, Ås, Norway.

Andersen-Ranberg, I. M., and B. Heringstad. 2006. Genetic associations between female fertility, mastitis and protein yield in Norwegian Red. Proc. 8th World Congr. Genet. Appl. Livest. Prod., Belo Horizonte, Brazil. Commun. no. 1-20.

Andersen-Ranberg, I. M., B. Heringstad, D. Gianola, Y. M. Chang, and G. Klemetsdal. 2005. Comparison between bivariate models for 56-day nonreturn and interval from calving to first insemination in Norwegian Red. J. Dairy Sci. 88:2190-2198.

Andersen-Ranberg, I. M., B. Heringstad, G. Klemetsdal, M. Svendsen, and T. Steine. 2003. Heifer fertility in Norwegian Dairy Cattle: Variance components and genetic change. J. Dairy Sci. 86:2706-2714.

Chang, Y. M., I. M. Andersen-Ranberg, B. Heringstad, D. Gianola, and G. Klemetsdal. 2006. Bivariate analysis of number of services to conception and days open in Norwegian Red using a censored threshold-linear model. J. Dairy Sci. 89:772-778.

Foulley, J. L., S. Im, D. Gianola, and I. Hoeschele. 1987. Empirical Bayes estimation of genetic value for $\mathrm{n}$ binary traits. Genet. Sel. Evol. 19:197-224.

Geno. 2006. Net Merit Index. Available http://www.geno.no/ Accessed May 26, 2006.

Gianola, D., and J. L. Foulley. 1983. Sire evaluation for ordered categorical data with a threshold model. Genet. Sel. Evol. 15:201-224.

Gianola, D., and D. Sorensen. 2004. Quantitative genetic models for describing simultaneous and recursive relationships between phenotypes. Genetics 167:1407-1424.

González-Recio, O., Y. M. Chang, D. Gianola, and K. A. Weigel. 2005. Number of inseminations to conception in Holstein cows using censored records and time-dependent covariates. J. Dairy Sci. 88:3655-3662. 
Hayes, J. F., R. I. Cue, and H. G. Monardes. 1992. Estimates of repeatability of reproductive measures in Canadian Holsteins. J. Dairy Sci. 75:1701-1706.

Heringstad, B., G. Klemetsdal, and J. Ruane. 2001. Responses to selection against clinical mastitis in the Norwegian Cattle population. Acta Agric. Scand., A Anim. Sci. 51:155-160.

Heringstad, B., R. Rekaya, D. Gianola, G. Klemetsdal, and K. A. Weigel. 2003. Genetic change for clinical mastitis in Norwegian Cattle: A threshold model analysis. J. Dairy Sci. 86:369-375.

Im, S., R. L. Fernando, and D. Gianola. 1989. Likelihood inferences from animal breeding data subject to selection. Genet. Sel. Evol. 21:399-414.

Kadarmideen, H. N., R. Thompson, and G. Simm. 2000. Linear and threshold model genetic parameters for disease, fertility and milk production in dairy cattle. Anim. Sci. 71:411-419.

Lund, M. S., J. Jensen, and P. H. Petersen. 1999. Estimation of genetic and phenotypic parameters for clinical mastitis, somatic cell deviance, and protein yield in dairy cattle using Gibbs sampling. J. Dairy Sci. 82:1045-1051.

Madsen, P., and J. Jensen. 2005. A User's Guide to DMU. Version 6, release 4.5. Research Centre Foulum, Tjele, Denmark.

Raftery, A. L., and S. Lewis. 1992. How many iterations in the Gibbs sampler? Pages 763-774 in Bayesian Statistics 4. J. M Bernando, J. O. Berger, A. P. Dawid, and A. F. M. Smith, ed. Oxford University Press, Oxford, UK.

Rodrigues Motta, M., D. Gianola, Y. M. Chang, and B. Heringstad. 2006. A zero-inflated Poisson model for genetic analysis of number of mastitis cases in Norwegian Red cows. Proc. 8th World Congr.
Genet. Appl. Livest. Prod., Belo Horizonte, Brazil. Commun. no. 26-05.

Roxström, A., E. Strandberg, B. Berglund, U. Emanuelson, and J. Philipsson. 2001. Genetic and environmental correlations among female fertility traits and milk production in different parities of Swedish Red and White dairy cattle. Acta Agric Scand., A Anim. Sci. 51:7-14.

Sorensen, D., and D. Gianola. 2002. Likelihood, Bayesian, and MCMC methods in quantitative genetics. Springer-Verlag, New York, NY.

Sørensen, M. K., J. Jensen, and L. G. Christensen. 2000. Udder conformation and mastitis resistance in Danish first-lactation cows: Heritabilities, genetic and environmental correlations. Acta Agric Scand., A Anim. Sci. 50:72-82.

Veerkamp, R. F., E. P. C. Koenen, and G. De Jong. 2001. Genetic correlations among body condition score, yield, and fertility in first-parity cows estimated by random regression models. J. Dairy Sci. 84:2327-2335.

Wall, E., S. Brotherstone, J. A. Woolliams, G. Banos, and M. P. Coffey. 2003. Genetic evaluation of fertility using direct and correlated traits. J. Dairy Sci. 86:4093-4102.

Zwald, N. R., K. A. Weigel, Y. M. Chang, R. D. Welper, and J. S. Clay. 2004a. Genetic selection for health traits using producerrecorded data. II. Genetic correlations, disease probabilities, and relationships with existing traits. J. Dairy Sci. 87:4295-4302.

Zwald, N. R., K. A. Weigel, Y. M. Chang, R. D. Welper, and J. S. Clay. 2004b. Genetic selection for health traits using producerrecorded data. I. Incidence rates, heritability estimates, and sire breeding values. J. Dairy Sci. 87:4287-4294. 